\title{
TIME EVOLUTION OF THE PROCESS OF DOPING OF SOLIDS BY PLASMA-ION BEAMS
}

\author{
A. Horodeński, C. PochrybniaK* \\ National Centre for Nuclear Research, ul. Andrzeja Soltana 7, 05-400 Otwock, Poland \\ * cezary.pochrybniak@ncbj.gov.pl
}

\begin{abstract}
Irradiation of a solid with intense plasma-ion beams produced within a high vacuum chamber (by the so-called Rod Plasma Injector [1]) is a strongly nonequilibrium process, which enables achieving a number of effects which are impossible to be achieved with other methods. These are, amongst other: improvement of ceramics wettability, fabrication of stable copper-ceramics interfaces and stable $\mathrm{Ni}-\mathrm{Cu}$ and $\mathrm{Al}-\mathrm{Cu}$ interfaces, improvement of tribological properties and high temperature oxidation resistance of stainless steel, photovoltaic junction formation, and many others. In the paper, the process of plasma-ion beam propagation regarding its time and energy distributions and the process of ion penetration of solids, resulting with ion implementation and temperature growth have been analyzed mathematically on basis of experimental data. Results of numerical calculations have been presented concerning temperature and dopant density time evolution.
\end{abstract}

Keywords: plasma, ion beam, implantation, doping, time evolution, energy distribution, stopping power.

\section{Introduction}

Irradiation of solids with so-called plasma-ion beams is a strongly nonequilibrium process, which enables a number of effects that are impossible to achieve with other methods [2]. These include improvement of wettability of ceramics [3-5], production of stable copper-ceramics interfaces [6], production of stable $\mathrm{Ni}-\mathrm{Cu}$ and $\mathrm{Al}-\mathrm{Cu}$ interfaces [7], improvement of properties of zirconium alloys [8], improvement of tribological properties of stainless steel [9], improvement of high temperature oxidation resistance of stainless steel [10], modification of superconducting and electrical properties of $\mathrm{Mg}-\mathrm{B}$ structures [11], improvement of manganese distribution in $\mathrm{Si}$ with $\mathrm{He}^{+}$and $\mathrm{H}^{+}$plasma pulse irradiation [12], doping metals with nitrogen [13], and photovoltaic junction formation [14].

The concept of the so-called Rod Plasma Injector (RPI) was proposed by Michał Gryziński $[1,15]$ and verified experimentally [16-19], including the recently set in operation IBIS-II RPI-type plasma generator [20]. The RPI is a very effective source of intense plasma-ion beams emitted in the form of short pulses of a duration of few microseconds, plasma density of the order of $10^{16} \mathrm{~cm}^{-3}$, and ion energy distribution up to several hundreds of $\mathrm{keV}$ - see Figs. 1-2. The process of ion propagation was initially analyzed in lit. [21].

A very important feature of the RPI device, which distinguishes it from other plasma devices, is the fact that the emission of the plasma jets takes place in a high vacuum (the order of $10^{-6}$ Torr), thus enabling an effective implantation process to be achieved.

\section{Ion-plasma beam propagation}

A complete set of ion emitting source parameters must consist of the following data:

1. total number of ions,

2. ion energy distribution,

3. ion start time distribution.

For numerical calculations (whose results are presented at the final part of the article), the following input data have been used:

1. energy distribution $f_{e}(\varepsilon)$ has the form shown in Fig. 1,

2. ion start time distribution $\Phi(\tau)$ has the form shown in Fig. 2,

3. having been accelerated within the plasma generator, ions move straightforward with uniform motion,

4. number of ions $N_{0}=5 \cdot 10^{12} \mathrm{~cm}^{-2}$, (see eq. (1))

5. target: silicon Si.

With initial conditions listed above, the total ontarget energy density is about $0.08 \mathrm{~J} / \mathrm{cm}^{2}$. An ion source can be understood as some surface $\Sigma$, which emits ions in accordance with the energy distribution $f_{e}(\varepsilon)$, and time distribution $\Phi(\tau)$. To begin with, we will consider an elementary ion "microsource" stretched over a surface element $\mathrm{d} \Sigma$, emitting ions within a time interval $[\tau, \tau+\mathrm{d} \tau]$ - see Fig. 3 .

The number of ions emitted from the "microsource" is equal to:

$$
\delta N=N_{0} d \Sigma \Phi(\tau) \mathrm{d} \tau
$$

The number of ions emitted from the "microsource" with an energy within $[\varepsilon, \varepsilon+\mathrm{d} \varepsilon]$ is:

$$
\mathrm{d} N=\delta N f_{e}(\varepsilon) \mathrm{d} \varepsilon
$$




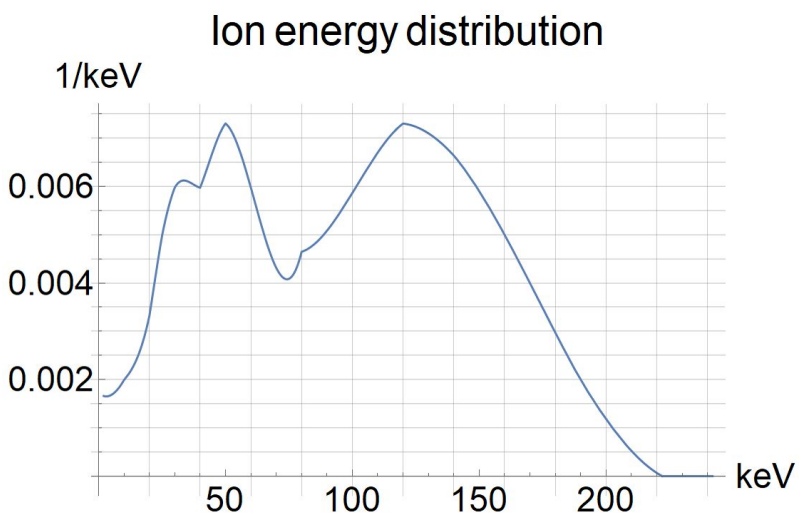

Figure 1. Interpolation curve of the measured energy distribution of ions [18]

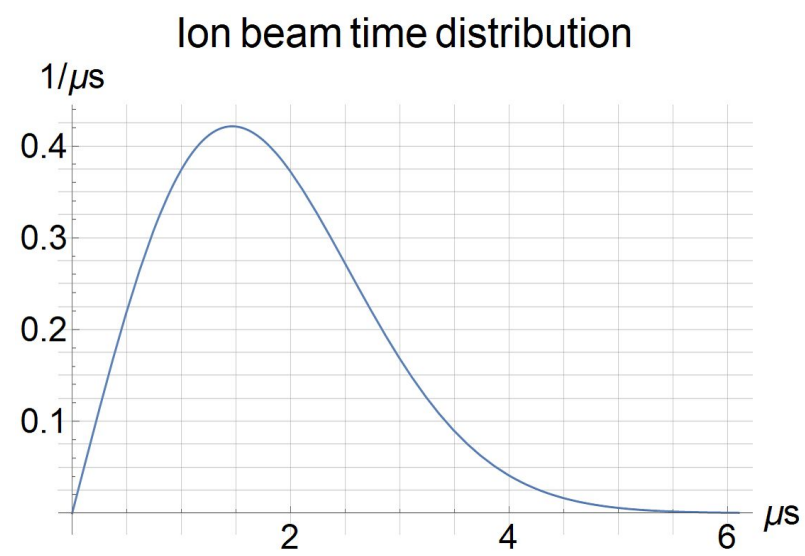

Figure 2. Gauss-type start time distribution of ions (established on the basis of RPI parameters)

Ions move from the source to a target along trajectories which can be expressed in terms of kinetic energy $\varepsilon$, flight time $\tau$, and position vector $z$ :

$$
\varepsilon=\frac{m z^{2}}{2(t-\tau)^{2}}
$$

In order to obtain expressions for on-target observables, one must transform the energy function $f_{e}$ into the respective time-of-flight distribution function at a fixed source-target distance:

$$
\begin{aligned}
f_{\tau}(t-\tau, z) & =f_{e}\left(\frac{m z^{2}}{2(t-\tau)^{2}}\right) \frac{\mathrm{d} \varepsilon}{\mathrm{d}(t-\tau)} \\
& =\frac{m z^{2}}{(t-\tau)^{3}} f_{e}\left(\frac{m z^{2}}{2(t-\tau)^{2}}\right) \quad(z=\text { const. })
\end{aligned}
$$

Now, the number of particles (from the "microsource") filling the volume element $\mathrm{d} V$ within the time interval $[\tau, \tau+\mathrm{d} \tau]$ can be calculated as:

$$
\mathrm{d} N=N_{0} d \Sigma f_{\tau}(t-\tau, z) \mathrm{d}(t-\tau) \Phi(\tau) \mathrm{d} \tau
$$

Taking into account geometrical relations:

$$
\frac{\mathrm{d} z}{\mathrm{~d}(t-\tau)}=\frac{z}{t-\tau}=v, \quad \mathrm{~d} V=\mathrm{d} z \mathrm{~d} S
$$

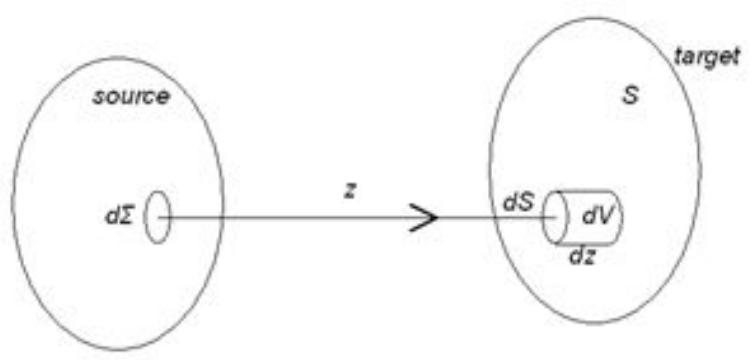

Figure 3. Differential scheme of free ion propagation
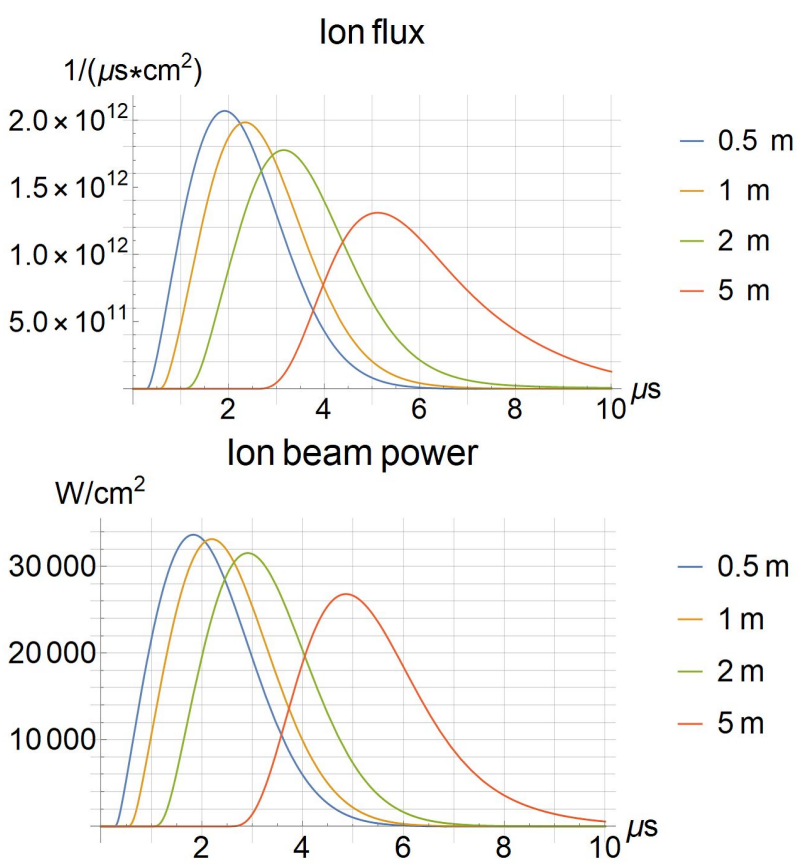

Figure 4. Temporary shapes of the flux (top) and power (bottom) of the plasma-ion beam at different distances from the plasma source.

we finally obtain the integral equation which connects ion source parameters with the on-target beam density, flux and power, respectively [22]:

$$
n(t, z)=m N_{0} \int_{0}^{t} \frac{z}{(t-\tau)^{2}} f_{e}\left(\frac{m z^{2}}{2(t-\tau)^{2}}\right) \Phi(\tau) \mathrm{d} \tau
$$

$J(t, z)=m N_{0} d \Sigma \int_{0}^{t} \frac{z^{2}}{(t-\tau)^{3}} f_{e}\left(\frac{m z^{2}}{2(t-\tau)^{2}}\right) \Phi(\tau) \mathrm{d} \tau$

$$
P(t, z)=\frac{1}{2} m^{2} N_{0} d \Sigma \int_{0}^{t} \frac{z^{4}}{(t-\tau)^{5}} f_{e}\left(\frac{m z^{2}}{2(t-\tau)^{2}}\right) \Phi(\tau) \mathrm{d} \tau
$$

The density of the energy deposited on a target is:

$$
E(z)=\int_{6}^{t} P(t, z) \mathrm{d} t
$$




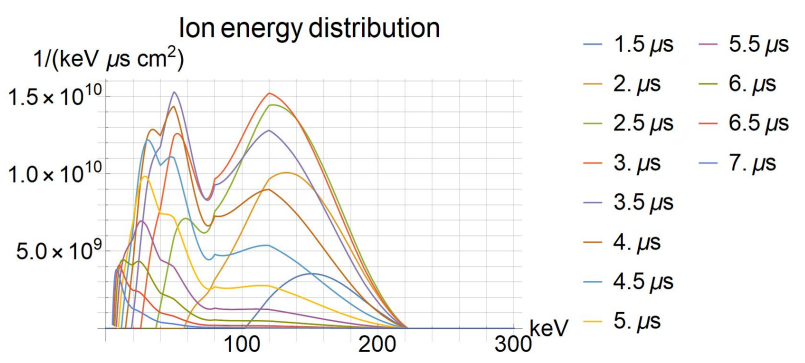

Figure 5. History of energy distribution of the flux of $B^{+}$ion beam approaching the target surface

\section{Time evolution of doping process}

The formulae derived above enable a numerical model to be constructed, which enables an immediate evaluation of the on-target ion flux shape at hand. Henceforth, it is possible to compute an evaluation of the implantation process parameters.

To achieve this goal, one has to "filter" the ion beam flux formula (8) using the energy dependent Dirac delta function:

$$
j(\varepsilon, t, z)=m N_{0} \int_{-\infty}^{+\infty} J(t, z) \delta\left(\varepsilon-\frac{m z^{2}}{2(t-\tau)^{2}}\right) \mathrm{d} \varepsilon
$$

From (11) we obtain, after some development, the time dependent energy distributed flux of ions approaching the target:

$$
j(\varepsilon, t, z)=m N_{0} \Phi\left(t-\sqrt{\frac{m z^{2}}{2 \varepsilon}}\right) f_{e}(\varepsilon)
$$

As seen above, the flux is elicited directly from ion source parameters, i.e. energy distribution, time distribution of the emission, and number of particles. An example of the flux of target approaching ions, computed at a series of time instants, is shown in Fig. 5.

Coupled with the parameters of the ion beam impinging the solid, formula (12) allows us to precisely compute details of the process of ion penetration of a target. As the result, we can achieve time dependent in-depth distributions of densities of doping ions, as well as a full history of the temperature distribution resulting from the energy released by ion irradiation.

During the solid penetration process, the temporary position of the ion depends on the material parameters and initial energy. It can be calculated with stopping power data [21]:

$$
z\left(\varepsilon_{0}, \varepsilon\right)=-\int_{\varepsilon_{0}}^{\varepsilon} \frac{\mathrm{d} \varepsilon}{S(\varepsilon)}
$$

where: $\varepsilon_{0}$ - initial energy value,

$\varepsilon-$ local energy value,

$S$ - stopping power function.

From (13) we immediately get the ion doping depth:

$$
z_{\text {dop }}\left(\varepsilon_{0}\right)=z\left(\varepsilon_{0}, 0\right)
$$

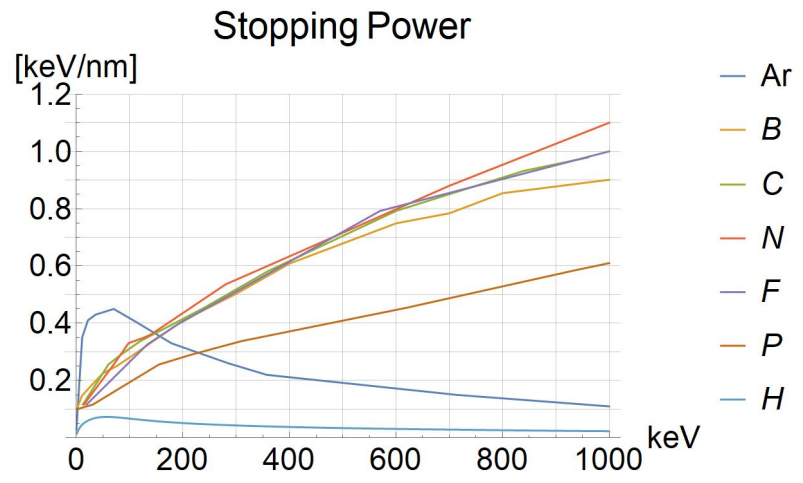

Figure 6. Stopping power of diverse ions in silicon (based on lit. [21])

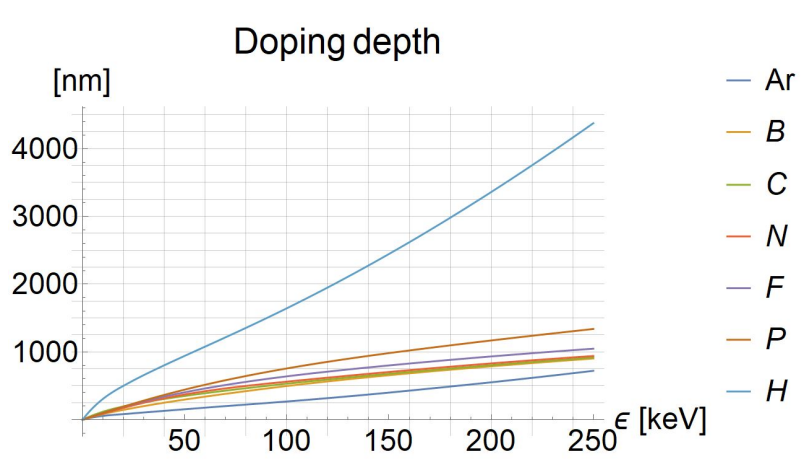

Figure 7. Doping depth of diverse ions in silicon vs. initial energy

Examples of a stopping power function shape of diverse ions penetrating a silicon wafer are shown in Fig. 6. An adequate dependence of the doping depth on the initial ion energy is shown in Fig. 7.

The above data makes it possible to estimate the duration of a single ion doping process :

$$
\tau=2 \delta\left(m / \varepsilon_{0}\right)^{1 / 2} \approx 10^{-12} \mathrm{~s}
$$

where:

$\delta$ - penetration depth,

$\varepsilon_{0}-$ initial energy,

$m$ - ion mass.

As seen above, the duration of the doping process is several orders of magnitude less than width of an ion pulse. Therefore, it can be assumed that the process of penetration, i.e. from impacting to stopping, is in fact an immediate one, „out of time”, within the actual time framework (on the order of $5 \mu \mathrm{s}$ ). This fact enables us to directly transform the initial energy of ions into an in-depth distribution. This can be done by an exchange of energy coordinate into position coordinate (prior to this, the reversed form of the function (14) must be found):

$$
j\left(\varepsilon_{0}, t\right)=j\left(\varepsilon_{0}(z), t\right) \frac{\mathrm{d} \varepsilon_{0}\left(z_{\mathrm{dop}}\right)}{\mathrm{d} z_{\mathrm{dop}}}
$$

From this, we can compute the in-depth dopant con- 

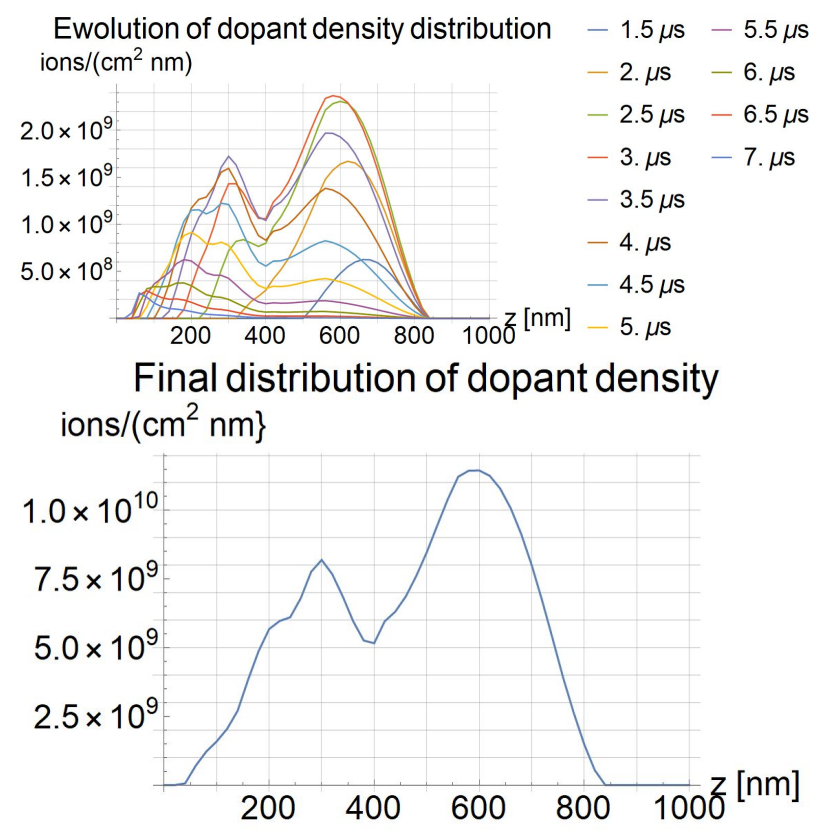

Figure 8. Top: time evolution of dopant density distribution. Bottom: final dopant density distribution $\left(B^{+}\right.$ ions in silicon). Distance between plasma source and the target is $2 \mathrm{~m}$.

centration:

$$
n(z, t)=\int_{0}^{t} j\left(\varepsilon_{0}\left(z_{\mathrm{dop}}\right), \tau\right) \frac{\mathrm{d} \varepsilon_{0}\left(z_{\mathrm{dop}}\right)}{\mathrm{d} z_{\mathrm{dop}}} \mathrm{d} \tau
$$

The calculated time evolution of a doping process is shown in Fig. 8.

\section{Time evolution of temperature distribution}

As shown by formula (15), the ion transfer from the surface to a certain position is much faster than the doping process time scale, therefore the position dependent ion energy loss depends solely on the initial energy of the ion. Therefore, the energy deposited at the ${ }^{\prime} z$ position is the sum of energies of all ions approaching this position within the time interval $[t, t+\mathrm{d} t]$

Hence, the total energy transferred to a solid by a group of ions with the energy of $[\varepsilon, \varepsilon+\mathrm{d} \varepsilon]$ and time interval $[t, t+\mathrm{d} t]$ at the position ' $z$ ' is equal to (the function $\varepsilon\left(z, \varepsilon_{0}\right)$ is elicited from formula (13)):

$$
\mathrm{d} Q\left(z, t, \varepsilon_{0}\right)=\mathrm{d} z \mathrm{~d} t j\left(\varepsilon_{0}, t, d\right) \frac{\mathrm{d} \varepsilon\left(z, \varepsilon_{0}\right)}{\mathrm{d} z} \mathrm{~d} \varepsilon_{0}
$$

From (18) we immediately achieve the temperature time evolution:

$$
T_{\mathrm{ref}}(z, t)=\frac{1}{\delta \gamma} \int_{0}^{t} \mathrm{~d} t \int_{\varepsilon_{0}}^{\varepsilon} j\left(\varepsilon_{0}, t, d\right) \frac{\mathrm{d} \varepsilon\left(z, \varepsilon_{0}\right)}{d z} \mathrm{~d} \varepsilon_{0}
$$

$d$ - distance between source and target,

$\delta$ - target stuff density,

$\gamma-$ specific heat.

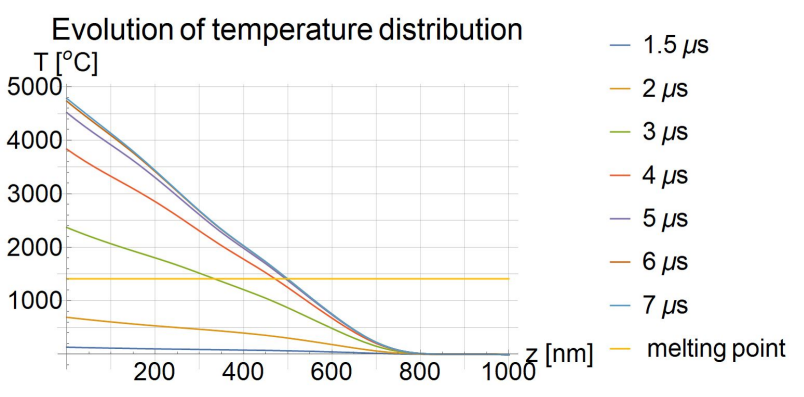

Figure 9. Time evolution of temperature distribution $\left(B^{+}\right.$in silicon). Distance between plasma source and the target is $2 \mathrm{~m}$.

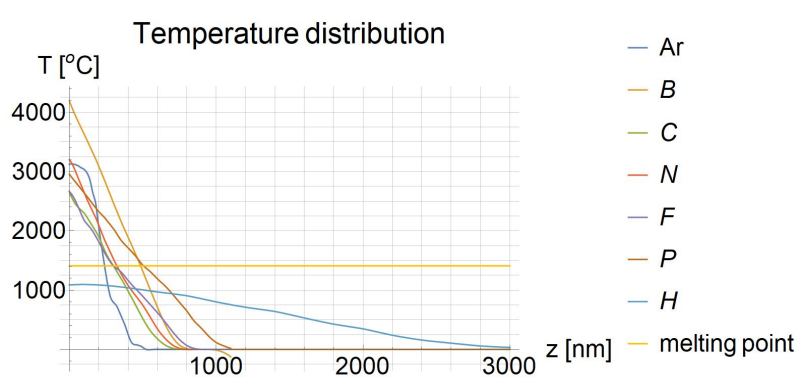

Figure 10. Final temperature distributions of silicon target irradiated with different ion beams

Expression (19) has an essential fault - it does not consider that the target substance melts. Consequently, it must be understood as only a sort of "reference temperature", which gives the basis for the final procedure of the real temperature computation which contains the process of melting. Finally, calculation is as follows:

$$
T(z, t)= \begin{cases}T_{\text {ref }}(z, t) & \text { if } T_{\text {ref }}<T_{\text {melt }} \\ T_{\text {melt }} & \text { if } T_{\text {melt }}<T_{\text {ref }}< \\ & <T_{\text {melt }}+\sigma_{\text {melt }} / \gamma \\ T_{\text {ref }}(z, t)-\sigma_{\text {melt }} / \gamma & \text { if } T_{\text {ref }}>T_{\text {melt }}+ \\ & +\sigma_{\text {melt }} / \gamma\end{cases}
$$

$T_{\text {melt }}$ - melting point,

$\sigma_{\text {melt }}-$ melting heat,

$\gamma-$ specific heat [23].

An example of calculation of in-depth temperature distribution is shown in Fig. 9.

Final results of silicon wafer irradiation with plasmaion beams consisting of diverse elements are shown in Figs. 10 and 11. As seen, parameters of doping processes with argon, boron, nitrogen, carbon, or fluorine ions are quite similar. At the same time, the hydrogen plasma reacts to silicon in quite a different way.

\section{Energy dissipation}

Accuracy of the presented model is disturbed by at least five dissipative processes: evaporation, infrared emission, heat flow, deionization and sputtering. 


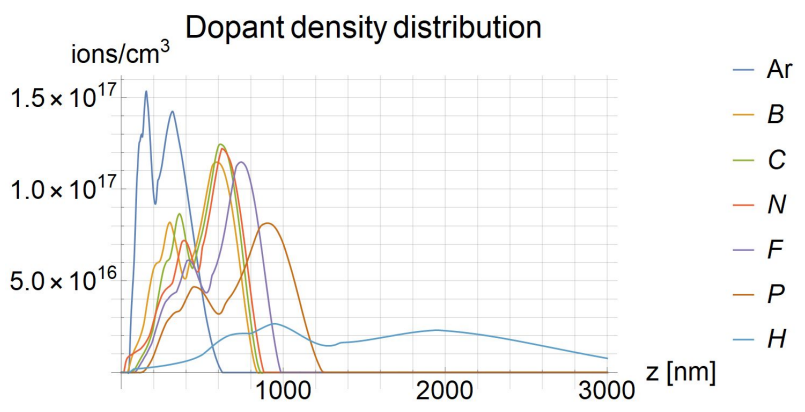

Figure 11. Final dopant density distributions at silicon target irradiated with different ion beams

i. Evaporation

$$
\frac{\partial q}{\partial t} \approx p \sqrt{3 \mathrm{kT} / \mathrm{m}} \approx 1.8 \cdot 10^{-3} \mathrm{~J} /\left(\mu \mathrm{scm}^{2}\right)
$$

$p$-equilibrium vapour pressure ( $\mathrm{Si}: 10^{4} \mathrm{~Pa}$ at $2700^{\circ} \mathrm{C}$ ) [24] $m$ - atom mass.

ii. Infrared emission

$$
\frac{\partial q}{\partial t} \approx \varepsilon \sigma T^{4} \approx 2.3 \cdot 10^{-4} \mathrm{~J} /\left(\mu \mathrm{scm}^{2}\right) \quad\left(\text { at } T=2700^{\circ} \mathrm{C}\right)
$$

$\varepsilon-$ emissivity (Si: $\varepsilon \approx 0.5[25]$ )

$\sigma$-Stefan-Boltzmann constant.

iii. Heat flow:

$$
\frac{\partial q}{\partial t}=-\lambda \frac{\partial T}{\partial z}
$$

$T$ - temperature,

$q$ - heat flux,

$\lambda$ - heat conductivity (Si: $148 \mathrm{~W} /(\mathrm{mK})$ ).

The heat flux, evaluated on the basis of the heat flow equation (21) at the temperature gradient of ca. $200 \mathrm{~K} / \mathrm{\mu m}$ (taken from Fig. 9), is:

$$
\frac{\partial q}{\partial t} \approx 3 \cdot 10^{-5} \mathrm{~J} /\left(\mu \mathrm{s} \mathrm{cm}^{2}\right)
$$

iv. Deionization Penetrating a solid body, ions are submitted to deionization process. Therefore they release the energy less or equal to their ionization potential:

$$
\frac{\partial q}{\partial t} \approx \varepsilon_{i} N_{0} / \Delta t \approx 5.8 \cdot 10^{-7} \mathrm{~J} /\left(\mu \mathrm{scm}^{2}\right)
$$

$\varepsilon_{i}$ - ionization potential of boron: $\varepsilon=8.3 \mathrm{eV}$.

v. Sputtering

$N_{\text {sputt }}=\varepsilon_{s} N_{0} \approx 1.6 \cdot 10^{12} \mathrm{~cm}^{-2} \quad(<1$ atomic layer $)$

$\varepsilon_{s}-$ sputter yield, $\left(\varepsilon_{s} \approx 0.33, \mathrm{~B}: \mathrm{Si}, 1-10 \mathrm{keV}\right)$ [26]

Within the analysed set of parameters sputtering process affects the solid surface within the extent of only 1 atomic layer, and therefore it can be regarded insignificant. Taking into account that the incoming energy flux is on the order of $2 \cdot 10^{-2} \mathrm{~J} /\left(\mu \mathrm{s} \mathrm{cm}{ }^{2}\right)$, we may assume that the dissipative processes mentioned above are too slow to have a significant influence on the process of ion doping. However, above $2700^{\circ} \mathrm{C}$ the influence of the evaporation heat flow (with a silicon target) is becoming significant.

\section{Conclusions}

Having the set of computation tools defined above, and within the assumed framework of initial parameters including energy distribution, emission pulse duration and pulse shape, number of ions, and the distance between plasma source and irradiated target, one can perform a credible comparison of doping processes of different ions. Further analysis will concern a significantly enlarged temperature (above $2500^{\circ} \mathrm{C}$ ) and time frames (from microseconds to milliseconds and more) in which the dissipative processes as well as dopant migration in the liquid phase of a solid will be taken into account.

\section{References}

[1] M. Gryziński. A new device for creating a strongly focused hot plasma jet-Rod Plasma Injector (RPI). Nukleonika, XIV(7-8):679-705, 1969.

[2] J. Piekoszewski, Z. Werner, C. Pochrybniak, J. Langner, M. Gryzinski, and A. Horodenski. Pulse Ion Beam Doping and Modification of Solids. Physica Status Solidi (a), 112(2):757-760, 1989. doi:10.1002/pssa.2211120237.

[3] M. Barlak, J. Piekoszewski, J. Stanisławski, Z. Werner, and K. Borkowska. The effect of intense plasma pulse pre-treatment on wettability in ceramic-copper system. Fusion Engineering and Design, 82(15-24):2524-2530, 2007. doi:10.1016/j.fusengdes.2007.08.010.

[4] M. Barlak, J. Piekoszewski, Z. Werner, and J. Stanislawski. Wettability improvement of carbon ceramic materials by mono and multi energy plasma pulses. Surface and Coatings Technology, 203(17-18):2536-2540, 2009. doi:10.1016/j.surfcoat.2009.02.070.

[5] M. Barlak, J. Piekoszewski, Z. Werner, B. Sartowska, W. Starosta, J. Kierzek, C. Pochrybniak, and E. Kowalska. Wettability of carbon and silicon carbide ceramics induced by their surface alloying with $\mathrm{Zr}$ and $\mathrm{Cu}$ elements using high intensity pulsed plasma beams. Nukleonika, 57(4):477-483, 2012.

[6] M. Barlak, W. Olesinska, J. Piekoszewski, Z. Werner, and M. Chmielewski. Ion beam modification of ceramic component prior to formation of $\mathrm{AlN}-\mathrm{Cu}$ joints by direct bonding process. Surface and Coatings Technology, 201(19-20):8317-8321, 2006. doi:10.1016/j.surfcoat.2006.01.090.

[7] J. Langner, J. Piekoszewski, C. Pochrybniak, F. Rosatelli, S. Rizzo, J. Kucinski, A. Miotello, L. A. Guzmán, and P. Lazzeri. Deposition by pulsed erosion of nickel and aluminum on copper. Surface and Coatings Technology, 66(1-3):300-304, 1994.

[8] B. Sartowska, W. Starosta, M. Barlak, and L. Waliś. Modification of zirconium alloy surface using high intensity pulsed plasma beams. Archives of Materials Science and Engineering, 77(2):53-57, 2016. doi:10.5604/18972764.1225592.

[9] B. Sartowska, J. Piekoszewski, L. Waliś, J. Senatorski, M. Barlak, and W. Starosta. Improvement of tribological properties of stainless steel by alloying its surface layer with rare earth elements using high 
intensity pulsed plasma beams. Surface and Coatings Technology, 205:S124-S127, 2011. doi:10.1016/j.surf coat.2011.04.082.

[10] J. Piekoszewski, B. Sartowska, M. Barlak, P. Konarski, and L. Dąbrowski. Improvement of high temperature oxidation resistance of AISI $316 \mathrm{~L}$ stainless steel by incorporation of Ce-La elements using intense pulsed plasma beams. Surface and Coatings Technology, 206(5):854-858, 2011.

doi:10.1016/j.surf coat.2011.03.104.

[11] J. Piekoszewski, W. Kempiński, M. Barlak, J. Kaszyński, and J. Stanisławski. Superconducting and electrical properties of $\mathrm{Mg}-\mathrm{B}$ structures formed by implantation of magnesium ions into the bulk boron followed by pulse plasma treatment. Vacuum, 81(10):1398-1402, 2007. doi:10.1016/j. vacuum. 2007.01.054.

[12] Z. Werner, C. Pochrybniak, M. Barlak, J. Piekoszewski, A. Korman, R. Heller, W. Szymczyk, and K. Bochenska. Implanted manganese redistribution in $\mathrm{Si}$ after $\mathrm{He}^{+}$irradiation and hydrogen pulse plasma treatment. Nukleonika, 56(1):5-8, 2011.

[13] J. Piekoszewski, J. Langner, J. Białoskórski, B. Kozłowska, C. Pochrybniak, Z. Werner, M. Kopcewicz, L. Waliś, and A. Ciurapiński. Introduction of nitrogen into metals by high intensity pulse ion beams. Nuclear Instruments and Methods in Physics, Research Section B Beam Interactions with Materials and Atoms, 80-81:344-347, 1993.

[14] J. Piekoszewski, M. Gryzinski, J. Langner, Z. Werner, and G. Huth. A new approach to photovoltaic junction formation by using pulse implantation doping technique. J. Phys. France, 43:1353-1358, 1982.

[15] M. Gryziński. Koncepcja prętowego (magnetoelektrycznego) działa plazmowego „DP”. Instytut Badań Jadrowych, Raport INR No 711 /XVIII/PP, Warszawa, 1966.

[16] J. Nowikowski and L. Jakubowski. Investigations of RPI in dynamic gas condition. Nukleonika, XXI(11-12):1227-1240, 1976.

[17] K. Malinowski. Experimental Investigation and Computer Simulations of an Ion Emission of the
RPI-IBIS Plasma Accelerator. PhD Thesis. National Center for Nuclear Research, 2012.

[18] E. Skladnik-Sadowska, M. Sadowski, and J. Baranowski. Investigation of convergent deuteron beams within a penetrable electrode system. Proc. 15th European Conf. on Controlled Fusion and Plasma Heating, Dubrovnik, 12B(Part II):633-636, 1988.

[19] M. Sadowski, J. Baranowski, E. Skladnik-Sadowska, V. Borisko, O. Byrka, V. Tereshin, and A. Tsarenko. Characterization of pulsed plasma-ion streams emitted from RPI-type devices applied for material engineering. Applied Surface Science, 238:433-437, 2004. doi:10.1016/j.apsusc. 2004.05.167.

[20] R. Kwiatkowski. Preliminary Measurements of Energy Distribution of Ions Emitted by IBIS-II Plasma Source. NCNR Internal Report, National Center for Nuclear Research, 2018.

[21] A. Horodeński. Evaluation of Pulse Shape of Ion Beams Produced by the Ionotron-Type Ion Sources. Physica Status Solidi (a), 112(2):821, 1989. doi:10.1002/pssa.2211120251.

[22] Stopping power of matter for ions. https: //www-nds.iaea.org/stopping/stopping_heav.html, Nuclear Data Services, International Atomic Energy Agency.

[23] New semiconductor materials. characteristics and properties. Ioffe Physico-Technical Institute, http:// www. ioffe.ru/SVA/NSM/Semicond/Si/thermal .html.

[24] Vapor pressure calculator. Technische Universität Wien, Institut für Angewandte Physik, https://www. iap.tuwien.ac.at/www/surface/vapor_pressure.

[25] N. M. Ravindra, B. Sopori, O. H. Gokce, S. X. Cheng, A. Shenoy, L. Jin, S. Abedrabbo, W. Chen, and Y. Zhang. Emissivity measurements and modeling of silicon-related materials: An overview. International Journal of Thermophysics, 22(5):1593-1611, 2001. doi:10.1023/A: 1012869710173.

[26] A simple sputter yield calculator. Technische Universität Wien, Institut für Angewandte Physik, https://www.iap.tuwien.ac.at/www/surface/ sputteryield. 